\title{
Barocaloric effect in ferroelastic fluorides and oxyfluorides
}

I.N. Flerov ${ }^{\mathrm{a}, \mathrm{b}}$, M.V. Gorev ${ }^{\mathrm{a}, \mathrm{b}}$, E.V. Bogdanov ${ }^{\mathrm{a}, \mathrm{c}}$, N.M. Laptash ${ }^{\mathrm{d}}$

${ }^{a}$ Kirensky Institute of Physics, Siberian Department of RAS, 660036 Krasnoyarsk, Russia

${ }^{b}$ Siberian Federal University, 660074 Krasnoyarsk, Russia

${ }^{c}$ Krasnoyarsk State Agrarian University, 660049 Krasnoyarsk, Russia

${ }^{d}$ Institute of Chemistry, Far Eastern Department of RAS, 690022 Vladivostok, Russia

e-mail: flerov@iph.krasn.ru 


\section{Barocaloric effect in ferroelastic fluorides and oxyfluorides}

Using the data about the temperature - pressure phase diagram and the phase transition entropy at ambient and high pressure, intensive and extensive barocaloric effects were analyzed in the region of single and successive order-disorder phase transitions in fluorides and oxyfluorides with the elpasolites-cryolite structure. It was found that hydrostatic as well as chemical pressure are the effective tools to change the entropy of compounds with disordered ionic groups or atoms in structure and to realize the significant intensive and extensive barocaloric effects comparable with the values of baro- and magnetocaloric effects, characteristic for materials, considered as promising solid refrigerants.

Keywords: phase transition; fluorides; oxyfluorides; thermal properties; barocaloric effect PACS numbers: 62.50.-p; 64.70.K-; 65.40.G-

\section{Introduction}

It can be considered with assurance that caloric effects (CE) in solids attract attention of scientific and engineering community during more than one and half centuries, beginning from the appearance of the papers by both W. Thomson Lord Kelvin and J.P. Joule devoted, particularly, to pioneering theoretical and experimental studies elastocaloric effect (ElCE) as a temperature response $\Delta T$ on the longitudinal compression/decompression $[1,2]$. However, despite the fact that ElCE, or, in other words, piezocaloric effect (PCE), in solids is the oldest one, over a long period of time the main attention of investigators was paid to the magneto(MCE)- and electro(ECE)-caloric effects [3-6]. There are at least two reasons of such a situation. The former is associated with rather strong difficulties to realize adiabatic conditions in the process with the applying/removal of uniaxial or hydrostatic pressure in experiments with the direct measurements of $\Delta T$. Only recently, some rather complicated installations were suggested for this aim $[7,8]$. The latter reason is better demonstrated using the thermodynamic equation of the Maxwell type [3]

$$
\left(\frac{\partial S}{\partial Y}\right)_{X}=\left(\frac{\partial X}{\partial T}\right)_{Y}
$$


where $X$ - generalized coordinate (order parameters: polarization, magnetization, linear or volume strain), $Y$ - generalized conjugated external field (electric, magnetic, uniaxial stress or hydrostatic pressure). The values of both extensive $\Delta S_{\mathrm{CE}}$ and intensive $\Delta T_{\mathrm{AD}} \mathrm{CE}$ depend on the external and internal parameters [3]

$$
\Delta S_{C E}=\int\left(\frac{\partial X}{\partial T}\right)_{Y} d Y, \quad \Delta T_{A D}=-\frac{T}{C_{Y}} \Delta S_{C E}
$$

where $C_{\mathrm{Y}}-$ heat capacity at $Y=$ const. Thus, the temperature derivative of the order parameter as an internal property of material plays very important role in the formation of its caloric response. The anomalously large value of $(\partial X / \partial T)_{Y}$ is characteristic for the vicinity of the phase transition point and at least magnetic transformations were known earlier than structural phase transitions in ferroelastics associated with BCE and PCE realized under hydrostatic and uniaxial pressure, respectively $[9,10]$. Namely therein is the second reason why MCE was studied more intensively.

On the other hand, it can be argued that BCE and PCE can be considered as very attractive properties because of many reasons. First, the following equation obtained from the combination of Eqs. (2)

$$
\Delta T_{A D}=\int V T \frac{\beta_{T}}{C_{p}} d p
$$

shows that both effects depending on the coefficient of the bulk $\beta_{\mathrm{T}}$ (or linear $\alpha_{\mathrm{T}}$ ) thermal expansion coefficient are universal properties for solids of any physical nature. Second, as a rule, phase transitions of different nature are sensitive to external pressure and BCE and PCE can be realized as additional effects to MCE or ECE in magnets and ferroelectrics [11-13]. Third, due to the magneto- and electroelastic interactions, BCE and PCE can be triggered as the secondary CE under variation of the magnetic or electric field [14]. And at last fourth, the most interesting peculiarity of $\mathrm{BCE}$, is that even in materials, belonging to one family, one 
can effect on the sign of the anomalous thermal expansion coefficient varying the chemical pressure by the cationic-anionic substitution and, as the result, transform the conventional $\mathrm{BCE}$ and PCE into inverse ones.

Recent reviews on CE of different physical nature $[15,16]$, have underlined that external hydrostatic pressure, up to the present, was mainly used as an instrument for tuning MCE and only episodically for BCE study [17 - 20]. The present paper is devoted to BCE in the family of complex fluorides and oxyfluorides with the octahedral anionic groups in structure, which is very rich of compounds undergoing ferroelastic phase transitions accompanied with large values of both the entropy change and baric coefficient $\mathrm{d} T / \mathrm{d} p$ [21]. The data obtained last years and some new results of analysis performed on materials studied by us earlier will be shortly reviewed and discussed in comparison with known solid coolants.

\section{Phase transitions and maximum barocaloric effects}

As postulated above, in accordance with Eqs. (2) - (3), the intensive and extensive BCE depend not only on the strength of hydrostatic pressure but also on the temperature derivative of the order parameter. In turn, the latter value can vary in wide range depending on the closeness of structural transformation to the tricritical point.

One more important question is associated with the internal and external reasons restricted the value of $\mathrm{CE}$ in distinct material or, in other words, what are the greatest possible values of CE? A schematic presentation in Fig. 1 demonstrates a process of determination of the extensive $\Delta S_{\mathrm{BCE}}{ }^{\max }$ and intensive $\Delta T_{\mathrm{AD}}{ }^{\max } \mathrm{BCE}$ maximum values in compounds undergoing structural phase transitions with the positive value of $\mathrm{d} T / \mathrm{d} p$. 

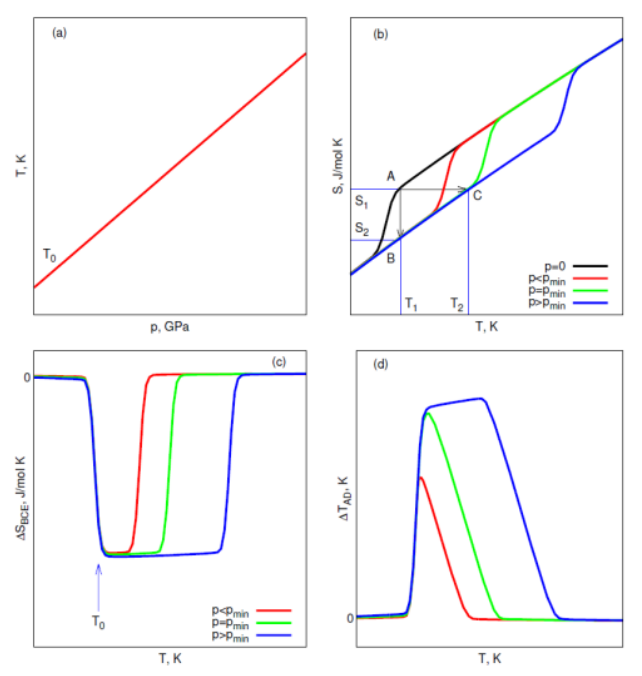

Figure 1. (a) T-p phase diagram. (b) Temperature and pressure dependences of the total entropy. (c, b) Temperature dependences of extensive and intensive BCE associated with selected hydrostatic pressures.

We will discuss BCE in ferroelastics characterized by strong ionic bonds. Therefore, one can confidently assume that pressure effects mainly on the behavior of the anomalous entropy $\Delta S$ associated with the change of the order parameter at the phase transitions. Rather low pressure used in our experiments $(p \leq 06 \mathrm{GPa})$ did not substantially change the entropy of other components, including regular lattice entropy $S_{\mathrm{L}}$. Therefore, the dependence $S_{\mathrm{L}}(T)$ determined at atmospheric pressure was used as the background entropy for the analysis of the pressure effect. The intensive and extensive BCE were determined using the experimental data on heat capacity at $p=0, T-p$ phase diagram as well as effect of pressure on the value and behavior of $\Delta S$ in a similar way to [10, 22].

After separation of the lattice part, $C_{\mathrm{L}}$, and anomalous contribution, $\Delta C_{\mathrm{p}}$, of the total heat capacity, $C_{\mathrm{p}}$, the information on the lattice $S_{\mathrm{L}}$ and anomalous $\Delta S$ entropies were obtained by integration of $C_{\mathrm{L}} / T$ ) and $\Delta C_{\mathrm{p}} / T$, respectively. Here it is pertinent to note that in accordance with $[23,24]$, the additional contribution into the Gibbs free energy due to external pressure has the form $p \eta^{2}$ ( $\eta$ - order parameter) contrary to $E P$ or $M H$ in the case of ferroelectrics and ferromagnets under electric or magnetic field. Such relation between $p$ and $\eta$ means only the 
shift of the transition temperature $\mathrm{T}_{0}$ under pressure without smearing the temperature behavior of $\eta$ and, consequently, the anomalous entropy.

That is why at $p>0$, the total entropy as a function of temperature and pressure (Fig. 1b) was determined by summation of the regular lattice entropy $S_{\mathrm{L}}$ and the anomalous contribution $\Delta S$ determined at $p=0$ and shifted along the temperature scale according to the $\mathrm{d} T / \mathrm{d} p$ value, obtained from the $T-p$ phase diagram (Fig. 1a). The DTA studies under low pressure $(p \leq 0.6 \mathrm{GPa}$ ) have shown that entropy of phase transitions in fluorides and oxyfluorides remains almost unchanged with pressure increase [10]. That means that there are neither significant changes in the degree of the proximity of phase transitions to the tricritical points nor changes in the numbers of equivalent orientational states of ionic groups in the initial and distorted phases.

Taking into account that both $\Delta S_{\mathrm{BCE}}$ and $\Delta T_{\mathrm{AD}}$ correspond to conditions $T=$ const and $S=$ const, respectively, analysis of the temperature and pressure dependences of the total entropy (Fig. 1b) allows one to determine value $\Delta S_{\mathrm{BCE}}(T, p)=S(T, p)-S(T, 0)$. The $\Delta T_{\mathrm{AD}}$ value was defined from equation $S(T, p)=S\left(T+\Delta T_{\mathrm{AD}}, 0\right)$.

Figures 1c and 1d show the qualitative behaviour of both BCE depending on temperature at $p>0: p<p_{\min } ; p \approx p_{\min }$ and $p>p_{\min }$. The $p_{\min }$ value is a minimum of pressure which produces the maximum values of BCE. Starting in the $T=$ const process from point A on the $S(T, p=0)$ curve to point B on the $S\left(T, p_{\min }\right)$ curve one can obtain $\Delta S_{\mathrm{BCE}}{ }^{\max }$ value, which is equal to the phase transition entropy $\Delta S$. In accordance with Eq. (2), the maximum value of the intensive BCE $\Delta T_{\mathrm{AD}}{ }^{\text {max }}$ is also limited by the $\Delta S$ value but depends on the $\left(\partial S_{\mathrm{L}} / \partial T\right)_{\mathrm{p}}$ derivative, i. e., on the temperature region where phase transition takes place. At pressure above $p_{\text {min }}$ both dependences $\Delta S_{\mathrm{BCE}}(T, p)$ and $\Delta T_{\mathrm{AD}}(T, p)$ have a plateau (Fig. 1c and 1d). This is very important peculiarity of BCE behaviour compared to ECE and MCE, which look in many cases like smeared peaks $[3,4,6]$. Because the $\Delta S$ value is proportional to the square of 
the order parameter, at least for ferroic phase transitions, it is obviously that the reasons of the limitation of the maximum CE of the different origin are the same.

Considering Fig. 1 in the case of the strong first order phase transition, one can obtain equations for row estimation of $\Delta T_{\mathrm{AD}}{ }^{\max }$ and $p_{\min }$ demonstrated their dependences on the value of baric coefficient

$$
\Delta T_{A D}^{\max }=\frac{d T_{0}}{d p} p_{\text {min }}, \quad p_{\text {min }} \geq \frac{T \Delta S}{C_{p} d T_{0} / d p}
$$

\section{Results and discussion}

Analysis above has shown the importance of large values of the phase transition entropy and baric coefficient in order to realize significant intensive and extensive BCE. Great values of $\Delta S$ accompany usually phase transitions associated either with orientational or positional disorder of some structural elements in initial high temperature phase, which disappeared through the process of structural distortion accompanied by the symmetry decrease [25]. As an illustrative example one can refer to the wide series of fluoro- and oxyfluoro-compounds with structure containing cationic and anionic polyhedra, which can be disordered by different ways $[21,26]$.

In accordance with the Clapeyron-Clausius $\mathrm{d} T / \mathrm{d} p=\delta V / \delta S$ and Ehrenfest $\mathrm{d} T / \mathrm{d} p=$ $T\left(\delta \beta / \delta C_{\mathrm{p}}\right)$ equations valid for phase transitions of the first and second order, respectively, both sign and value of $\mathrm{d} T / \mathrm{d} p$ depend on the sign and value of the relation between the jumps of volume $\delta V$ and entropy $\delta S$ as well as thermal expansion coefficient $\delta \beta$ and heat capacity $\delta C_{\mathrm{p}}$, which occur at phase transition point [25]. Depending on the composition and the relation between symmetry of the initial and distorted phases, complex fluorides and oxyfluorides can undergo phase transitions accompanied by increase or decrease of the unit cell volume upon heating and, thus, demonstrate positive or negative baric coefficient. Moreover, rather often some of these compounds exhibit two or more successive structural 
transformations associated with the volume change characterized by the opposite sign of $\mathrm{d} T / \mathrm{d} p$.

Let us consider some remarkable results obtained in studies of BCE in crystals of the elpasolite-cryolite type having cubic symmetry Fm-3m and undergoing structural phase transitions under temperature and/or pressure variation. For example a series of compounds with general chemical formula $\mathrm{Rb}_{2} \mathrm{KMeO}_{\mathrm{x}} \mathrm{F}_{6-\mathrm{x}}(\mathrm{x}=0,1,3)$ are known to undergo one first order ferroelastic phase transition below room temperature and characterized by the simple $T$ $-p$ phase diagram like it is schematically shown in Fig. 1a [21, 27]. Table 1 demonstrates that changing chemical pressure by variation of the central atom size and the relation between $\mathrm{F}$ and $\mathrm{O}$ atoms, one can change the temperature, entropy as well as baric coefficient typical for structural transformation.

\section{[Insert Table 1 near here]}

Taking into account that the $\Delta S_{\mathrm{BCE}}{ }^{\max }$ value is almost equal to $\Delta S$ of phase transition and using the approach discussed in the previous section, the intensive $\mathrm{BCE} \Delta T_{\mathrm{AD}}{ }^{\mathrm{max}}$ and corresponding $p_{\min }$ values were determined. It seen that in spite of the rather wide range of the maximum $\mathrm{BCE}$ quantities, the $p_{\min }$ values are a little bit different for the $\mathrm{Rb}_{2} \mathrm{KMeO}_{\mathrm{x}} \mathrm{F}_{6-\mathrm{x}}$ elpasolites. One of the possible reasons of this fact is that phase transitions in crystals under consideration are characterized by the different chemical pressure and by the different closeness to the tricritical point.

The total substitution of spherical cations $\mathrm{Rb}_{2} \mathrm{~K}$ for tetrahedral ammonium group, on the one hand, does not change the Fm-3m symmetry and, on the other, leads to a significant increase of the phase transition temperature (Table 1). Entropy of phase transition in oxyfluorides was changed to a lesser extent compared to very high increase of the $\Delta S$ value in ammonium fluorides. Such a situation is due to a strong different degree of disordering the $\mathrm{NH}_{4}$ groups giving additional contribution into anomalous entropy of fluorides $[21,26]$. It is 
not improbable that configuration of polyhedra $\mathrm{MeO}_{3} \mathrm{~F}_{3}$ also effects on the limitation of disorder in a cubic phase of oxyfluorides.

As to the baric coefficient, its value is strongly decreased in ammonium compounds with $\mathrm{Ga}$ and $\mathrm{Ti}$, whereas, in $\left(\mathrm{NH}_{4}\right)_{3} \mathrm{MoO}_{3} \mathrm{~F}_{3}$ this parameter became anomalously large. However, unlike pure ferroelastic phase transition in the $\mathrm{Rb}_{2} \mathrm{KMeO}_{\mathrm{x}} \mathrm{F}_{6-\mathrm{x}}$, structural transformation in ammonium molybdate is complicated of origin showing ferroelastic and ferroelectric properties [29].

Using Eq. (4) the values of the intensive $\Delta T_{\mathrm{AD}}{ }^{\max } \mathrm{BCE}$ as well as $p_{\min }$ were determined not for all ammonium compounds analyzed because of some reasons. First, experimental data on $\mathrm{d} T_{0} / \mathrm{d} p$ for $\left(\mathrm{NH}_{4}\right)_{3} \mathrm{FeF}_{6}$ are absent. Second, both $\left(\mathrm{NH}_{4}\right)_{3} \mathrm{TiOF}_{5}$ and $\left(\mathrm{NH}_{4}\right)_{3} \mathrm{GaF}_{6}$ are characterized by the presence of triple points on $T$ - $p$ phase diagrams at rather low pressure $p_{\text {trp }} \approx 0.18 \mathrm{GPa}[30,32]$, which prevent to reach the maximum barocaloric parameters.

Comparison of the maximum and experimentally observed values of both BCE shows rather good agreement. Some difference between $p_{\min }$ and experimental pressure $p^{\exp }$ for the same compound is particularly associated with the validity of Eqs. (4) for strong first order phase transitions, whereas compounds under consideration undergo transformations close to the tricritical point.

Many of the fluorides and oxyfluorides with the elpasolite-cryolite structure undergo successive phase transitions at ambient pressure and show at $p>0$ the triple points on the $T-p$ phase diagram where intermediate phases disappeared/appeared [21, 26]. In other compounds, as it was pointed above, rather low pressure splits one phase transition observed at $p=0$. In the case of complicated $T-p$ phase diagrams, the change in the total entropy as a function of temperature and pressure was determined by summing the lattice component of the entropy $S_{\mathrm{L}}(T)$ and anomalous entropies $\Delta S(T, p)$ associated with distinct phase transition 
and found from the DTA measurements under pressure and then scaled in magnitude on the basis the anomalous entropies obtained from the direct measurements of the heat capacity.
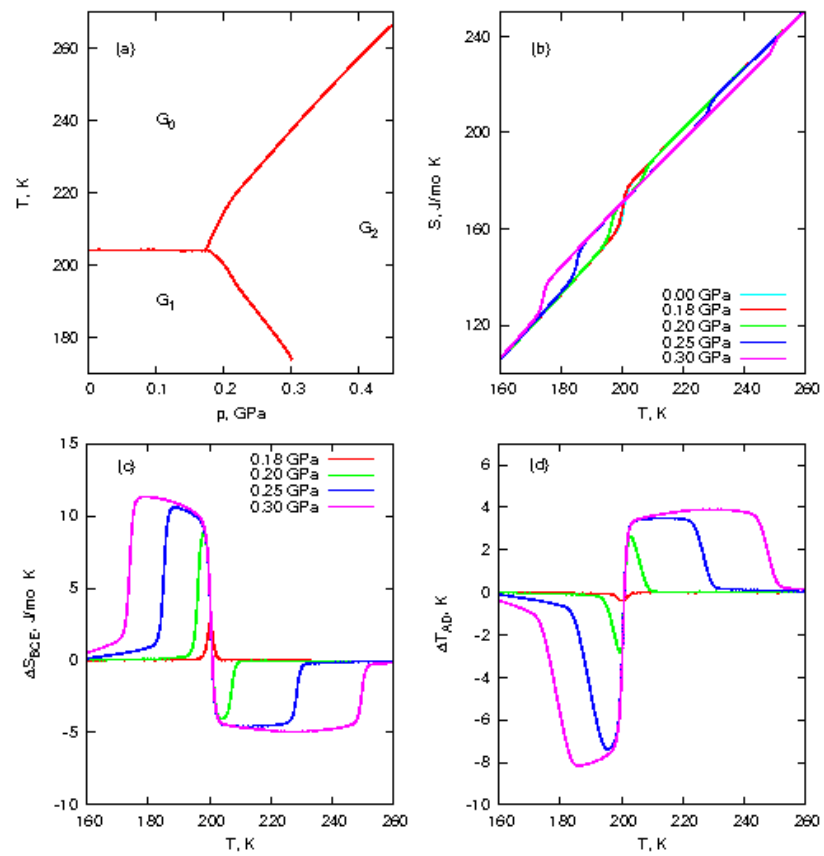

Figure 2. (a) $T-p$ phase diagram of $\left(\mathrm{NH}_{4}\right)_{3} \mathrm{WO}_{3} \mathrm{~F}_{3}$. (b) Temperature and pressure dependences of the total entropy $S=S_{\mathrm{L}}+\Delta S$. (c, b) Temperature dependences of extensive and intensive $\mathrm{BCE}$ associated with selected hydrostatic pressures.

The $T-p$ phase diagram presented in Fig. 2a demonstrates very impressive example of gigantic changing a sensitivity of the $\left(\mathrm{NH}_{4}\right)_{3} \mathrm{WO}_{3} \mathrm{~F}_{3}$ crystal to the hydrostatic pressure [30]. At pressure below triple point $\left(p_{\text {trp }}=0.183 \mathrm{GPa}\right.$ ), baric coefficient is very small $\mathrm{d} T / \mathrm{d} p_{\mathrm{G} 0 \leftrightarrow \mathrm{G} 1}$ $=-2.5 \pm 5 \mathrm{~K} / \mathrm{GPa}$. That is why in spite of rather large entropy change $\left(\Delta S_{\mathrm{G} 0 \leftrightarrow \mathrm{G} 1}=16.9\right.$ $\mathrm{J} / \mathrm{mol} \cdot \mathrm{K}$ ) the intensive an extensive $\mathrm{BCE}$ are insignificant at direct transition between $\mathrm{G}_{0}$ and $\mathrm{G}_{1}$ phases at $p=0.18 \mathrm{GPa}$ (Fig. 2c). After splitting of the $\mathrm{G}_{0} \leftrightarrow \mathrm{G}_{1}$ phase transition on to two successive transformations $\mathrm{G}_{0} \leftrightarrow \mathrm{G}_{2}\left(\Delta \mathrm{S}_{\mathrm{G} 0 \leftrightarrow \mathrm{G} 1}=6.4 \mathrm{~J} / \mathrm{mol} \cdot \mathrm{K}\right)$ and $\mathrm{G}_{2} \leftrightarrow \mathrm{G}_{1}\left(\Delta \mathrm{S}_{\mathrm{G} 0 \leftrightarrow \mathrm{G} 1}=\right.$ $10.5 \mathrm{~J} / \mathrm{mol} \cdot \mathrm{K}$ ), baric coefficients became anomalously large: + $435 \mathrm{~K} / \mathrm{GPa}$ and $-252 \mathrm{~K} / \mathrm{GPa}$, respectively. As the result, in the $p>p_{\text {trp }}$ region, the $S(T, p)$ dependences associated with successive phase transitions are rather complicated (Fig.2b). 
Contrary to oxyfluoride $\left(\mathrm{NH}_{4}\right)_{3} \mathrm{WO}_{3} \mathrm{~F}_{3}$, fluoride $\left(\mathrm{NH}_{4}\right)_{3} \mathrm{ScF}_{6}$ with the same cubic symmetry Fm-3m undergoes three successive phase transitions at ambient pressure [32] (Fig. 3a). The $\mathrm{G}_{2} \leftrightarrow \mathrm{G}_{3}$ transformation is of a displacive type accompanied by insignificant entropy change $\Delta S_{\mathrm{G} 2} \leftrightarrow \mathrm{G} 3=0.8 \mathrm{~J} / \mathrm{mol} \cdot \mathrm{K}$. Therefore only the $\mathrm{G}_{0} \leftrightarrow \mathrm{G}_{1}\left(\Delta S_{\mathrm{G} 0 \leftrightarrow \mathrm{G} 1}=14\right.$ $\mathrm{J} / \mathrm{mol} \cdot \mathrm{K})$ and $\mathrm{G}_{1} \leftrightarrow \mathrm{G}_{2}\left(\Delta S_{\mathrm{G} 1 \leftrightarrow \mathrm{G} 2}=7 \mathrm{~J} / \mathrm{mol} \cdot \mathrm{K}\right)$ phase transitions of the order-disorder type attracted interest to the BCE study. The pressure increase narrows the temperature intervals of the intermediate phases and at about $p_{\text {trp } 1}=0.5 \mathrm{GPa}$ the $\mathrm{G}_{1}$ phase disappears. The $S(T, p)$ dependences for $\left(\mathrm{NH}_{4}\right)_{3} \mathrm{ScF}_{6}$ look like those for $\left(\mathrm{NH}_{4}\right)_{3} \mathrm{WO}_{3} \mathrm{~F}_{3}$ but with the opposite directions of the $\Delta S$ shift along $S_{\mathrm{L}}$ in accordance with the sign of $\mathrm{d} T / \mathrm{d} p$ (Fig. 3b).
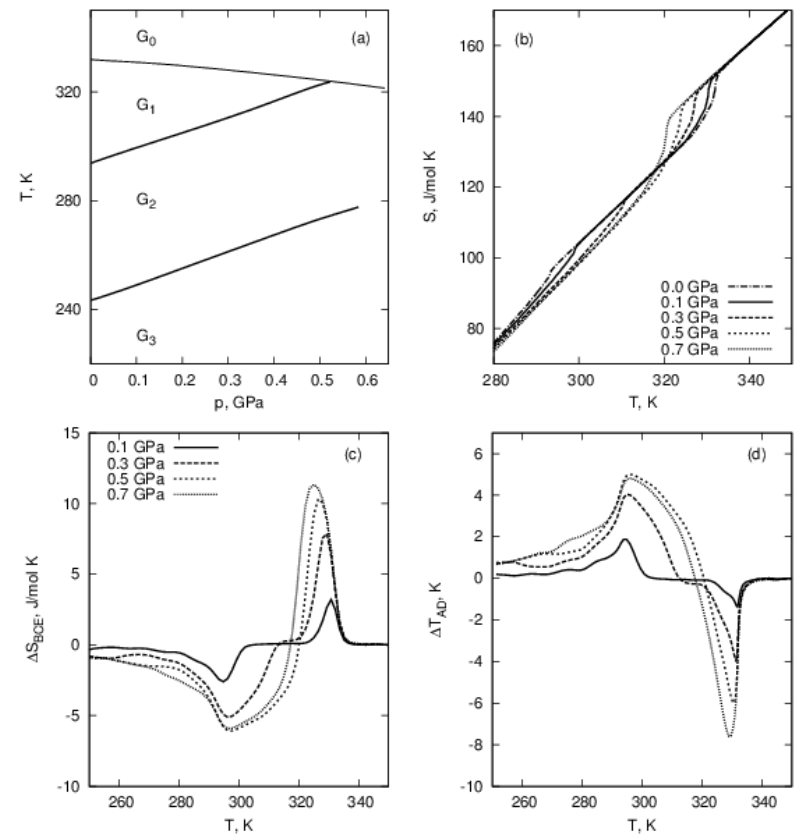

Figure 3. (a) T-p phase diagram of $\left(\mathrm{NH}_{4}\right)_{3} \mathrm{ScF}_{6}$. (b) Temperature and pressure dependences of the total entropy $S=S_{\mathrm{L}}+\Delta S$. (c, d) Temperature dependences of extensive and intensive BCE associated with selected hydrostatic pressures.

In Fig. 3 c, d one can see that scandium fluoride exhibits large enough negative $\left(\Delta T_{\mathrm{AD}} \approx-8 \mathrm{~K}\right)$ and positive $\left(\Delta T_{\mathrm{AD}} \approx 5 \mathrm{~K}\right)$ intensive $\mathrm{BCE}$ in the narrow temperature range $\sim$ (280-340 K) due to specific shape of phase diagram (Fig. 3b). Left peak on the $\Delta S_{\mathrm{BCE}}(T, p)$ 
and $\Delta T_{\mathrm{AD}}(T, p)$ dependences reaches the saturation at $p_{\mathrm{trp} 1}$, whereas right peak increases with the lowering rate even at $0.8 \mathrm{GPa}$. Similar situation was observed on the same dependences of $\left(\mathrm{NH}_{4}\right)_{3} \mathrm{WO}_{3} \mathrm{~F}_{3}(\mathrm{Fig}, 2 \mathrm{c}, \mathrm{d})$.

The existence of two phase transitions in one crystal in the narrow temperature range accompanied by different sign of $\mathrm{d} T / \mathrm{d} p$ is very attractive phenomenon, which can be considered as perspective for designing solid coolants of new generation. Indeed, the application of pressure to $\left(\mathrm{NH}_{4}\right)_{3} \mathrm{ScF}_{6}$ at temperature close, from the left side, to the intersection point of the $\Delta T_{\mathrm{AD}}(T)$ and $\Delta T_{\mathrm{AD}}=0$ lines on the $\Delta T_{\mathrm{AD}}(T)$ diagram leads to the temperature increase (Fig. 3 d). At particular parameters, the sample can change the symmetry and, as the result, transfer to the right side of the intersection point, which will be accompanied by the temperature decrease at the same pressure. Removal of pressure will decrease temperature of the sample and initiate its returning to the left side in relation to the intersection point.

In Table 1 the BCE parameters of complex fluorides and oxyluorides are also compared with those for some alloys and intermetallic compounds. First of all one can see that the maximum extensive $\mathrm{BCE}$ is again the largest for ammonium fluorides and oxyfluorides. The absence of the heat capacity data did not allows one to estimate the $\Delta T_{\mathrm{AD}}{ }^{\text {max }}$ quantities for alloys and intermetallic compounds. At the same time the $\Delta T_{\mathrm{AD}}{ }^{\text {exp }}$ values for these materials determined at rather low pressure $p^{\text {exp }}$ is significantly lower. It worth to note that the $\left(\mathrm{NH}_{4}\right)_{2} \mathrm{SO}_{4}$ ferroelectric shows comparable $\Delta S_{\mathrm{CE}}{ }^{\text {exp }}$ due to orderdisorder phase transition (Table 1) [33]. But the $\Delta T_{\mathrm{AD}}{ }^{\exp }$ value is almost half as much compared even to $\mathrm{Rb}_{2} \mathrm{KMeO}_{\mathrm{x}} \mathrm{F}_{6-\mathrm{x}}$ crystals with lower values of $\Delta S_{\mathrm{CE}}{ }^{\max }$.

One can compare also BCE in compounds under study with MCE in $\mathrm{Fe}_{49} \mathrm{Rh}_{51}$ and $\mathrm{Gd}_{5} \mathrm{Si}_{2} \mathrm{Ge}_{2}$ considered as promising solid refrigerants [4]. In order to realize comparable entropy and temperature change in both magnets, rather high magnetic field $(2-5) \mathrm{T}$ is 
needed (Table 1). We think, one can agree with statement presented in [16] concerning BCE and PCE in comparison with MCE: "As compared to magnetic cooling, the major advantage of mechanical refrigeration lies in that the driving stress necessary for refrigeration cycle (several hundred $\mathrm{MPa}$ ) is much easier and less expensive to obtain than the driving magnetic field (several T)".

\section{Conclusions}

In this paper, we briefly considered BCE in solids which is rather poor investigated compared to MCE and ECE. Intensive and extensive barocaloric parameters were analyzed in some fluorides and oxyfluorides undergoing structural phase transitions of the order-disorder type. It was shown that depending on the chemical pressure changed by the cationic-anionic substitution one can:

(1) Significantly vary the succession and temperatures of phase transitions as well as distribution of entropy between several transformations and, as the result; extensive BCE

(2) Change the value and sign of the baric coefficient and consequently transform conventional BCE into inverse.

(3) Realize two phase transitions with the opposite sign of BCE in the narrow temperature range, which is rather attractive from the view of new conception of designing solid state refrigerants.

The results of the CE comparison in compounds under study and some other materials show that the fluorides and oxyfluorides with the elpasolites-cryolite structure can be considered as the promising solid refrigerants. 


\section{Funding}

The reported study was partially supported by the Russian Foundation for Basic Research (RFBR), research project No. 15-02- 02009 a. 


\section{References}

1. W. Thomson, On the thermoelastic and thermomagnetic properties of matter, Part I. Quart. J. Math. (April 1855).

2. J. P. Joule, On some thermo-dynamic properties of solids. Phil. Trans. 149, 91-131 (1859).

3. A. M. Tishin, Y. I. Spichkin, The magnetocaloric effect and its applications. London: Taylor \& Francis Ltd (2003).

4. K. A. Gschneidner, V. K. Pecharsky, A. O. Tsokol, Recent developments in magnetocaloric materials. Rep. Prog. Phys. 68, 1479-1539 (2005).

5. Y. V. Sinyavski, G. E. Lugansky, N. D. Pashov, Electrocaloric refrigeration: investigation of a mode, and prognosis of mass and efficiency index. Cryogenics. 32, 28-31 (1992).

6. M. Valant, Electrocaloric materials for future solid-state refrigeration technologies. Prog. Mater. Sci. 57, 980-1009 (2012).

7. L. N. Dzhavadov, Yu. I. Krotov, Measurement of (delta-T-delta-p)S for solids and liquids under pressure to $3 \mathrm{GPa}$. Instruments and Experimental Techniques 28, 687-690 (1985).

8. L. Mañosa, D. González-Alonso, A. Planes, E. Bonnot, M. Barrio, J. -L. Tamarit, S. Aksoy, M. Acet, Giant solid-state barocaloric effect in the Ni-Mn-In magnetic shapememory alloy. Nature Mater. 9, 478 - 481 (2010).

9. M. V. Gorev, E. V. Bogdanov, I. N. Flerov, A. G. Kocharova, N. M. Laptash, Investigation of thermal expansion, phase diagrams, and barocaloric effect in the $\left(\mathrm{NH}_{4}\right)_{2} \mathrm{WO}_{2} \mathrm{~F}_{4}$ and $\left(\mathrm{NH}_{4}\right)_{2} \mathrm{MoO}_{2} \mathrm{~F}_{4}$ oxyfluorides. Phys. Solid State 52, 167-175 (2010).

10. M. V. Gorev, I. N. Flerov, E. V. Bogdanov, V. N. Voronov, N. M. Laptash, Barocaloric effect near the structural phase transition in the $\mathrm{Rb}_{2} \mathrm{KTiOF}_{5}$ oxyfluoride. Phys. Solid State 52, 377-383 (2010).

11. E. A. Mikhaleva, I. N. Flerov, V. S. Bondarev, M. V. Gorev, A. D. Vasiliev, T. N. Davydova, Phase transitions and caloric effects in ferroelectric solid solutions of ammonium and rubidium hydrosulfates. Phys. Solid State 53, 510-517 (2011).

12. E. A. Mikhaleva, I. N. Flerov, M. V. Gorev, M. S. Molokeev, A. V. Cherepakhin, A. V. Kartashev, N. V. Mikhashenok, K. A. Sablina, Caloric characteristics of $\mathrm{PbTiO}_{3}$ in the temperature range of the ferroelectric phase transition Phys. Solid State 534, 18321840 (2012).

13. A. V. Kartashev, E. A. Mikhaleva, M. V. Gorev, E. V. Bogdanov, A. V. Cherepakhin, K. A. Sablina, N. V. Mikhashonok, I. N. Flerov, N. V. Volkov, Thermal properties, 
magneto- and baro-caloric effects in $\mathrm{La}_{0.7} \mathrm{~Pb}_{0.3} \mathrm{MnO}_{3}$ single crystal. J. Appl. Phys. 113, 073901 (2013).

14. I. N. Flerov, E. A. Mikhaleva, M. V. Gorev, A. V. Kartashev, Caloric and multicaloric effects in oxygen ferroics and multiferroics. Phys. Solid State 57, 429-441 (2015).

15. X. Moya, S. Kar-Narayan, N. D. Mathur, Caloric materials near ferroic phase transitions. Nature Materials 13, 439-450 (2014).

16. B. Lu, J. Liu, Mechanocaloric materials for solid-state cooling. Sci. Bull. 60, 1638-1643 (2015).

17. L Mañosa, D. González-Alonso, A. Planes, E. Bonnot, M. Barrio, J.-L. Tamarit, S. Aksoy and M. Acet, Giant solid-state barocaloric effect in the Ni-Mn-In magnetic shapememory alloy. Nature Mater. 9, 478-481 (2010).

18. S. Yuce, M. Barrio, B. Emre, E. Stern-Taulats, A. Planes, J.-L. Tamarit, Y. Mudryk, K.

A. Gschneidner, Jr.,V. K. Pecharsky, L. Mañosa, Barocaloric effect in the magnetocaloric prototype $\mathrm{Gd}_{5} \mathrm{Si}_{2} \mathrm{Ge}_{2}$. Appl. Phys. Lett. 101, 071906 (2012).

19. E. Stern-Taulats, A. Planes, P. Lloveras, M. Barrio, J.-L Tamarit, S. Pramanick, S. Majumdar, C. Frontera, L. Mañosa, Barocaloric and magnetocaloric effects in $\mathrm{Fe}_{49} \mathrm{Rh}_{51}$. Phys. Rev. B 89, 214105 (2014).

20. D. Matsunami, A. Fujita, K. Takenaka, M. Kano, Giant barocaloric effect enhanced by the frustration of the antiferromagnetic phase in $\mathrm{Mn}_{3} \mathrm{GaN}$. Nature Mater. 14, 73-78 (2015).

21. I. N. Flerov, M. V. Gorev, M. S. Molokeev, N. M. Laptash, Ferroelastic and ferroelectric phase transitions in fluoro - and oxyfluorometallates. In: A. Tressaud, K. Poeppelmeier, eds. Photonic and electronic properties of fluoride materials. Progress in fluorine science series. Amsterdam, Oxford, Cambridge: Elsevier; 355-381 (2016).

22. T. Strässle, A. Furrer, Z. Hossain, C. Geibel, Magnetic cooling by the application of external pressure in rare-earth compounds. Phys. Rev.B 67, 054407 (2003).

23. K.S. Aleksandrov, A.T. Anistratov, B.V. Beznosikov, N.V. Fedoseeva, Phase transitions of halide $A B X_{3}$ compounds. Novosibirsk: Nauka (1981).

24. K. M. Rabe, Ch. H.Ahn, J.-M. Triscone, eds. Physics of Ferroelectrics. A Modern Perspective. Springer-Verlag Berlin Heidelberg (2007).

25. N. G. Parsonage, L A. K. Staveley. Disorder in Crystals. Oxford: Clarendon Press, 1978.

26. I. Flerov, M. Gorev, K. Aleksandrov, A. Tressaud, J. Grannec, M. Couzi, Phase transitions in elpasolites (ordered perovskites). Materials Science and Engineering: R: Reports 24, 81-151 (1998). 
27. E. I. Pogorel'tsev, E. V. Bogdanov, M. S. Molokeev, V. N. Voronov, L. I. Isaenko, S. A. Zhurkov, N. M. Laptash, M. V. Gorev, I. N. Flerov, Thermodynamic properties and structure of oxyfluorides $\mathrm{Rb}_{2} \mathrm{KMoO}_{3} \mathrm{~F}_{3}$ and $\mathrm{K}_{2} \mathrm{NaMoO}_{3} \mathrm{~F}_{3}$. Phys. Solid State 53, 12021211 (2011).

28. I. N. Flerov, M. V. Gorev, A. Tressaud, N. M. Laptash, Perovskite-like fluorides and oxyfluorides: Phase transitions and caloric effects. Cryst. Reports 56, 9-17 (2011).

29. I. N. Flerov, V. D. Fokina, A. F. Bovina, E. V. Bogdanov, M. S. Molokeev, A. G. Kocharova, E. I. Pogorel'tsev, N. M. Laptash, Mechanism and nature of phase transitions in the $\left(\mathrm{NH}_{4}\right)_{3} \mathrm{MoO}_{3} \mathrm{~F}_{3}$ oxyfluoride. Phys. Solid State 50, 515-524 (2008).

30. I. N. Flerov, M. V. Gorev, V. D. Fokina, A. F. Bovina, N. M. Laptash, Calorimetric and $\mathrm{X}$-ray diffraction studies of the $\left(\mathrm{NH}_{4}\right)_{3} \mathrm{WO}_{3} \mathrm{~F}_{3}$ and $\left(\mathrm{NH}_{4}\right)_{3} \mathrm{TiOF}_{5}$ perovskite-like oxyfluorides. Phys. Solid State 46, 915-921 (2004).

31. K. Moriya., T. Matsuo, H. Suga, S. Seki,. On the phase transition of ammonium hexafluoroferrate (III). Bull. Chem. Soc. Japan. 50, 1920-1926 (1977).

32. M. V. Gorev, I. N. Flerov, A. Tressaud, Thermodynamic properties and $p-T$ phase diagrams of $\left(\mathrm{NH}_{4}\right)_{3} \mathrm{M}^{3+} \mathrm{F}_{6}$ cryolites $\left(\mathrm{M}^{3+}: \mathrm{Ga}, \mathrm{Sc}\right)$. J. Phys.: Condensed Matter 11, 7493 (1999).

33. P. Lloveras, E. Stern-Taulats, M. Barrio, J.-Ll. Tamarit, S. Crossley, W.Li, V. Pomjakushin, A. Planes, Ll. Manosa, N.D. Mathur and X. Moya, Giant barocaloric effects at low pressure in ferrielectric ammonium sulphate. Nat. Commun. 6, 1-6 (2015). 


\section{Figure Captions}

Figure 1. (a) $T-p$ phase diagram. (b) Temperature and pressure dependences of the total entropy. (c, b) Temperature dependences of extensive and intensive BCE associated with selected hydrostatic pressures.

Figure 2. (a) $T$ - $p$ phase diagram of $\left(\mathrm{NH}_{4}\right)_{3} \mathrm{WO}_{3} \mathrm{~F}_{3}$. (b) Temperature and pressure dependences of the total entropy $S=S_{\mathrm{L}}+\Delta S$. (c, b) Temperature dependences of extensive and intensive BCE associated with selected hydrostatic pressures.

Figure 3. (a) T-p phase diagram of $\left(\mathrm{NH}_{4}\right)_{3} \mathrm{ScF}_{6}$. (b) Temperature and pressure dependences of the total entropy $S=S_{\mathrm{L}}+\Delta S$. (c, d) Temperature dependences of extensive and intensive BCE associated with selected hydrostatic pressures. 
Table 1. Thermodynamic parameters of the phase transition and barocaloric characteristics of fluorides and oxyfluorides with the elpasolite-cryolite structure compared to BCE and MCE in some alloys and ferroics. * - this work.

\begin{tabular}{|c|c|c|c|c|c|c|c|c|c|c|}
\hline Compound & $T_{0}, \mathrm{~K}$ & $\begin{array}{l}\mathrm{d} T_{0} / \mathrm{d} p \\
\mathrm{~K} / \mathrm{GPa}\end{array}$ & $\begin{array}{c}\Delta S_{\mathrm{CE}}^{\max }, \\
\mathrm{J} / \mathrm{kg} \cdot \mathrm{K}\end{array}$ & $\frac{\Delta T_{\mathrm{AD}}{ }^{\max },}{\mathrm{K}}$ & $\begin{array}{l}p_{\min } \\
\mathrm{GPa}\end{array}$ & $\begin{array}{c}\Delta S_{\mathrm{CE}}{ }^{\exp }, \\
\mathrm{J} / \mathrm{kg} \cdot \mathrm{K}\end{array}$ & $\begin{array}{c}\Delta T_{\mathrm{AD}}{ }^{\exp }, \\
\mathrm{K}\end{array}$ & $\begin{array}{l}p^{\exp } \\
\text { GPa }\end{array}$ & $\begin{array}{c}H, \\
\mathrm{~T}\end{array}$ & Ref. \\
\hline $\mathrm{Rb}_{2} \mathrm{KMoO}_{3} \mathrm{~F}_{3}$ & 195 & 117 & -34.8 & 17.6 & 0.15 & -30.4 & 16 & 0.4 & & 27 \\
\hline $\mathrm{Rb}_{2} \mathrm{KTiOF}_{5}$ & 215 & 110 & -47 & 19 & 0.2 & -43 & 16 & 0.4 & & 10 \\
\hline $\mathrm{Rb}_{2} \mathrm{KFeF}_{6}$ & 198 & 132 & -41 & 15.6 & 0.2 & -41 & 16 & 0.2 & & 28 \\
\hline $\mathrm{Rb}_{2} \mathrm{KGaF}_{6}$ & 123 & 112 & -36.5 & 11.6 & 0.1 & - 35.9 & 11.2 & 0.2 & & $*$ \\
\hline$\left(\mathrm{NH}_{4}\right)_{3} \mathrm{MoO}_{3} \mathrm{~F}_{3}$ & 297 & 202 & -54 & 14.2 & 0.1 & -54 & 15 & 0.4 & & 29 \\
\hline$\left(\mathrm{NH}_{4}\right)_{3} \mathrm{TiOF}_{5}$ & 265 & 6.3 & -84.5 & & & & & & & 30 \\
\hline$\left(\mathrm{NH}_{4}\right)_{3} \mathrm{FeF}_{6}$ & 267 & & $( \pm) 111$ & & & & & & & 31 \\
\hline$\left(\mathrm{NH}_{4}\right)_{3} \mathrm{GaF}_{6}$ & 250 & -12 & 94.5 & & & & & & & 32 \\
\hline $\mathrm{Mn}_{3} \mathrm{GaN}$ & 290 & -65 & 22.3 & & & 22.3 & -4.8 & 0.14 & & 20 \\
\hline Ni-Mn-In & 290 & 17.3 & -27 & & & -24.4 & 4.5 & 0.26 & & 17 \\
\hline $\mathrm{Fe}_{49} \mathrm{Rh}_{51}$ & 308 & 64 & -12.5 & & & $\begin{array}{l}-12 \\
-12\end{array}$ & & 0.20 & 2 & 19 \\
\hline $\mathrm{Gd}_{5} \mathrm{Si}_{2} \mathrm{Ge}_{2}$ & 260 & 3.6 & -20.4 & & & $\begin{array}{l}-11 \\
-19\end{array}$ & $\begin{array}{l}1.1 \\
15\end{array}$ & 0.2 & 5 & 18 \\
\hline$\left(\mathrm{NH}_{4}\right)_{2} \mathrm{SO}_{4}$ & 219 & -45 & 60 & & & 60 & -8 & 0.1 & & 33 \\
\hline
\end{tabular}


